\title{
Evaluation of the Expression of HER2 and c-KIT Proteins as Prognostic Markers in Superficial Bladder Urothelial Carcinoma
}

\author{
Wael Abdou Hassan' \\ Essam Shalaby (iD ${ }^{2}$ \\ Mona Abo-Hashesh ${ }^{3}$ \\ Rehab Ibrahim $\mathrm{Ali}^{4,5}$ \\ 'Department of Basic Sciences, College \\ of Medicine, Suliman Al Rajhi University, \\ Al Bukayriyah, Kingdom of Saudi Arabia; \\ ${ }^{2}$ Department of Urology, Faculty of \\ Medicine, Suez Canal University, Ismailia, \\ Egypt; ${ }^{3}$ Faculty of Science, Port Said \\ University, Port Said, Egypt; ${ }^{4}$ Department \\ of Pathology, College of Medicine, El-Jouf \\ University, Sakaka, Kingdom of Saudi \\ Arabia; ${ }^{5}$ Department of Pathology, \\ Faculty of Medicine, Suez Canal \\ University, Ismailia, Egypt
}

Background: The roles of c-KIT and HER2 protein expression in bladder cancer are still debated, and the prognostic value of these proteins as markers of tumor progression is inconclusive.

Objective: To assess the impact of HER2 and c-KIT protein expressions in the progression of non-muscle-invasive bladder cancer.

Methods: All patients undergoing transurethral resection of bladder tumors for non-muscleinvasive urothelial carcinoma, with standard regimen of BCG, between January 2017 and November 2019, were evaluated pathologically and immunohistochemically for HER1 and c-KIT proteins in urothelial carcinoma cells. Follow-up cystoscopy was performed for 100 patients every 3 months for the first 2-years and any recurred tumors were excised and examined pathologically, as well as stained for HER2 and c-KIT protein expression.

Results: HER2 and c-KIT positive expressions were detected in $49 \%$ and $38 \%$ of cases, respectively. After a mean follow-up of $26.4 \pm 7.2$ months, the overall recurrence and progression rates were significantly correlated with overexpression of HER2 and c-KIT. In highgrade non-invasive muscle neoplasms, tumor cells showed weak expression for both HER2 and c-KIT proteins, but with progression to muscle-invasion, tumor cells strongly expressed HER2 and lost expression to c-KIT. In the multivariate model, overexpression of HER2 rather than c-KIT protein significantly predicted increased progression.

Conclusion: Recurrence and progression of non-muscle-invasive bladder cancer correlate with overexpression of HER2 and c-KIT proteins in tumor cells.

Keywords: urothelial carcinoma, non-muscle-invasive, c- KIT, HER2

\section{Introduction}

Bladder cancer is one of the worldwide most common malignancies of the urinary tract, representing $90 \%$ of all high morbidity and mortality urothelial carcinoma. ${ }^{1}$ The World Health Organization classified bladder cancer into non-infiltrating and infiltrating carcinoma, ${ }^{2}$ which is subdivided into muscle-invasive (MIBC) and nonmuscle-invasive bladder cancer (NMIBC); the latter includes a non-invasive papillary lesion (Ta), carcinoma in situ (CIS), or superficial invasive lesion to the lamina propria (T1). ${ }^{2}$

Selection of appropriate treatment for bladder cancer depends on patient age, tumor grade, pathological stage, and concomitant CIS. Despite undergoing transurethral resection of bladder tumor (TURBT) with intravesical Bacillus CalmetteGuérin (BCG), high-grade NMIBC tends to recur in $23-74 \%$ and progress to
Correspondence: Wael Abdou Hassan Department of Basic Sciences, College of Medicine, Suliman Al Rajhi University, PO Box 777, Al Bukayriyah, 5194I, Kingdom of Saudi Arabia Tel +966-163169000

Email w.hassan@sr.edu.sa 
muscle-invasive disease in $33-50 \%$ of patients. ${ }^{3,4}$ Highgrade tumors have residual remnants in $45-76 \%$ of patients at the time of re-resection. ${ }^{5,6} \mathrm{~A}$ second TURBT resection for T1 high-grade bladder cancer is recommended within 2-6 weeks after initial resection, with close surveillance strategy. ${ }^{7}$

Different outcomes are observed in patients with the same grade and stage, highlighting the role of biomarkers expression in carcinogenesis and probably management procedures. $^{8}$ The proto-oncogene c-KIT encodes a transmembrane tyrosine kinase receptor, which is involved in carcinogenesis. It is overexpressed in the gastrointestinal stromal tumor, breast carcinoma, and lung small cell carcinoma. ${ }^{9}$ However, its role in bladder cancer has not been thoroughly investigated. ${ }^{9-11}$

Similarly, human epidermal factor receptor 2 (HER2) is a proto-oncogene that is often overexpressed in the progression of various tumors, including breast and gastric cancers. ${ }^{10-13}$ The wide variability of HER2 overexpression in bladder cancer has been reported, especially in highgrade tumors. ${ }^{13}$ However, the roles of c-KIT and HER2 expression in NMIBC are still unclear, and their prognostic value as markers of tumor progression is inconclusive. This study assesses the diagnostic benefit of c-KIT and HER2 expression in NMIBC and their correlation with tumor recurrence and/or progression.

\section{Methods}

\section{Study Design}

This is a prospective clinical study, including 100 patients undergoing TURBT for NMIBC at two academic centers between January 2017 and November 2019. Patients' characteristics and management strategy were recorded, including age, gender, comorbid conditions, date of diagnosis, frequency of follow-up cystoscopies \pm TURBTs performed, intra-vesical therapy, time to recurrence and/or progression, and last follow-up visit. All methods were performed following the relevant guidelines and regulations of Suez Canal university with IRB no (4169) and written consent was obtained from all patients who participated in the study.

\section{The Strategy of Management and Surveillance}

Patients underwent initial urethra-cystoscopy and tumor characteristics were recorded: tumor location, size, multiplicity, and shape. TURBT was performed accordingly, with resection of papillary tumors with the underlying muscle layer and sent for pathological assessment. A second TURBT ${ }^{14,15}$ was performed for all patients with T1 tumors, CIS, and high-grade disease, for more accurate staging, especially in cases with missing detrusor muscle in the initial sampling. Follow-up cystoscopy was performed every 3-month for all $\mathrm{T} 1$ and high-grade Ta tumors for 2-year. In patients with low-grade $\mathrm{Ta}$ cancer, the first cystoscopy was performed after 3-month and then annually unless there was documented progression. All patients received an early single dose of Epirubcine $50 \mathrm{mg}$ within 6-hour of primary resection. Two-week after TURBT, the standard regimen of a 6-week induction course of BCG (ImmuCyst ${ }^{\circledR} 81 \mathrm{mg}$ freeze-dried preparation) was administered in all patients with T1, CIS, and Ta high-grade tumors, followed by maintenance BCG, when appropriate.

\section{Primary Endpoints}

The primary endpoints of the study were tumor recurrence and stage progression of NMIBC. Recurrence was defined as any visible bladder growth during follow-up cystoscopy with the same stage, which has been documented by histopathological studies. Progression was defined as an increased pathological stage of the primary disease to invade the lamina propria and/or the muscle propria or the development of the metastatic disease.

\section{Histopathological Evaluation, Staining, and Scoring}

Samples were fixed with $10 \%$ formalin and embedded in paraffin. Histological sections were submitted and stained with hematoxylin and eosin (H\&E) to confirm the diagnosis and identify tumor grade and depth of invasion according to the latest WHO classification. ${ }^{2}$ Additional sections were prepared for immunohistochemical (IHC) staining. Primary antibodies (Supplementary Table) were purchased from Genemed (San Francisco, USA).

HER2 and c-KIT protein membranous and cytoplasmic expressions in tumor cells were the main variables of interest. The following semi-quantitative method was used to assess the staining intensity; a strong positive result will be defined as strong or moderate immunoreactivity in $50 \%$ or more of the cells (Score $2+$ ), a weak positive result will be defined as mild immunoreactivity or staining of fewer than $50 \%$ of tumor cells (Score $1+$ ) and cells with faint or no staining will be scored as negative (Score 0). 
All primary tumors that were excised during initial urethra-cystoscopy and/or second TURBT were examined pathologically. NMIBC cases were immunohistochemically stained for HER2 and c-KIT proteins. Any recurrent tumors during period of follow up was pathologically analyzed, and additionally examined for HER2 and c-KIT proteins and compared to the primary resected tumors.

\section{Data Analysis}

JMP9 software program (SAS Institute Inc, Cary, NC) was used to perform data analysis. Ordered logit estimation was done by Stata 15 software. Categorical variables were presented as numbers and percentages, while quantitative data were presented in terms of means \pm SD. Pearson's Chi-square or Fisher's exact tests were used to test the significance of the difference between categorical variables. Mann-Whitney $U$-test was used to compare continuous variables. The receiver operating characteristics (ROC) curve calculated the predictive values of the protein expression and a two-tailed $\mathrm{p}$-value of $<0.05$ was accepted as statistically significant differences.

\section{Results}

After the exclusion of six patients: three patients lost follow-up and another three patients were found to have MIBC in the second look TURBT, the final results are based on 100 patients. During the follow-ups, we observed one of three cases: no lesion, recurrence, or a strong lesion. The main variables of interest are HER2 and c-KIT proteins, wherein these proteins can be absent, weakly expressed, or strongly expressed. The analysis also contained several control variables that are hypothesized to affect the patients during the follow-up period, these are the patients' age, sex, and if CIS exist or not, along with the size, appearance, and site of the tumor. The sample comprised 53 female patients and the majority are aged 60 and above. Single tumors were more common than multiple, with tumor size in most cases were larger than $3 \mathrm{~cm}$. T1 and Ta tumors were in 55\% and $45 \%$ of patients, respectively, and concomitant CIS in 2 patients with $\mathrm{T} 1 \mathrm{high}$ grade. In the second look TURBT, the remaining patients had the same stage. HER2 and c-KIT positive expression were detected in $49 \%$ and $38 \%$ of the studied NMIBC cases respectively, including concomitant positive expression of both proteins in $22 \%$ of cases. The demographic data and tumor characteristics were summarized in Table 1. Patients who experienced no recurrence or
Table I Demographic Data, Pathological Features, and Tumor Outcomes

\begin{tabular}{|c|c|c|}
\hline \multicolumn{2}{|l|}{ Variables } & No (\%) \\
\hline \multicolumn{2}{|l|}{ Mean age/years (range) } & $62(45-72)$ \\
\hline \multirow[t]{2}{*}{ Gender } & Males & $74(74)$ \\
\hline & Females & $26(26)$ \\
\hline \multirow[t]{2}{*}{ Location of tumor } & Bladder walls & $8 I(8 I)$ \\
\hline & Bladder neck & $19(19)$ \\
\hline \multirow[t]{2}{*}{ Appearance of tumor } & Papillary & $78(78)$ \\
\hline & Nodular & $22(22)$ \\
\hline \multirow[t]{2}{*}{ Size of tumor } & $\leq 3 \mathrm{~cm}$ & $54(54)$ \\
\hline & $>3 \mathrm{~cm}$ & $46(46)$ \\
\hline \multirow[t]{2}{*}{ Multiplicity } & Single & $84(84)$ \\
\hline & $\geq 2$ & $16(16)$ \\
\hline \multirow[t]{2}{*}{ Tumor grade } & Low-grade & $53(53)$ \\
\hline & High-grade & $47(47)$ \\
\hline \multirow[t]{2}{*}{ Tumor stage } & $\mathrm{Ta}$ & $45(45)$ \\
\hline & TI & $55(55)$ \\
\hline \multicolumn{2}{|c|}{ Concomitant carcinoma in situ (CIS) with TI } & $2(2)$ \\
\hline \multicolumn{2}{|c|}{ Mean time of follow-up/months (Mean $\pm S D$ ) } & $26.4 \pm 7.2$ \\
\hline \multirow[t]{2}{*}{ HER2 } & Negative & $5 I(5 I)$ \\
\hline & Positive & $49(49)$ \\
\hline \multirow[t]{2}{*}{ c-KIT } & Negative & $62(62)$ \\
\hline & Positive & $38(38)$ \\
\hline Concomitant HER2\&c-KIT & Positive & $22(22)$ \\
\hline
\end{tabular}

progression showed no or weak expression of both HER2 and c-KIT proteins $(0+)$. When comparing changes of the primary and secondary pattern of the HER 2 and c-KIT protein expression in bladder tumors at the time of recurrence and progression, we found that at the time of recurrence there was no change in the mean score of both protein expressions in Ta \&T1. On the progression of Ta tumors to T1, both proteins showed a mild decrease in low-grade relative to high-grade tumors. When progressing from $\mathrm{T} 1$ to muscle invasion, in low-grade NMIBC, tumor nests showed moderate expression of HER2 and weak focal expression of c-KIT. When progressing to lowgrade muscle invasion, tumor nests showed reduced HER2 protein expression and absent expression for c-KIT. On the other hand, in high-grade NMIBC, tumor nests showed 
weak and focal expression of both HER2 and c-KIT proteins. When progressing to high-grade muscle invasion, tumor cells retained stronger expression of HER2 protein and lost expression for c-KIT (Figure 1).

The overexpression of HER2 protein was significantly associated with patients younger than 60-year-old and tumors larger than $3-\mathrm{cm}$. Overexpression of both markers was significantly associated with higher tumor grade and stage (Table 2). The predicted probabilities of recurrence and progression of the primary tumor concerning the level of expression of HER2 and c-KIT proteins were presented in Tables 3 and 4. The probability of experiencing recurrence and progression increases gradually with increasing protein expression.

Several control variables that may affect the outcome were included in the multivariate regression model, including the patient's age and the primary tumor characteristics, such as size, number, the gross appearance of the tumor, and the association of other mucosal abnormalities. Also, overexpression of HER2 and c-KIT protein significantly predicted increased recurrence and/or progression during follow-up by 6.25 and 4.8 -times respectively (Tables 4 and 5 ). In terms of the marginal effects, the predicted probability of experiencing no recurrence was $92 \%$ if no HER2 protein was observed, and then started decreasing gradually until reaching $24 \%$ when protein is strongly expressed.

In nonparametric ROC curves, despite the worthless prognostic accuracy of HER2 in the assessment of recurrence (Figure 2A), the test showed good to excellent prognostic accuracy of HER2 protein expression in detecting progression status (Figure 2B), with corresponding sensitivity and specificity of $84.72 \%$ and $80.65 \%$.

\section{Discussion}

For decades the intra-vesical BCG has become the gold standard treatment for high-grade NMIBC. However, early or deferred radical cystectomy with urinary diversion represents an alternative treatment option for these patients with heterogeneous prognosis secondary to the significantly high-risk of recurrence and progression, even after post-TURBT intravesical therapy. ${ }^{3}$ Therefore, it is crucial to correctly and timely identify those patients with highrisk tumors and those with poor or no response to intravesical therapy.

The transmembrane proto-oncogenes HER2 and c-KIT are members of the receptor tyrosine kinases and can dictate cancer-related events. ${ }^{16}$ However, there is controversy about their prognostic value in NMIBC, where the literature strives for large prospective clinical studies for homogeneous series of patients to confirm such prognostic value in bladder cancer. Therefore, this study fills a gap in the literature and investigates the prognostic benefits and correlation of both protein expression in NMIBC with tumor recurrence and/or progression.

In the present study, there is a significant correlation between the detection of both HER2 and c-KIT proteins and the increased recurrence and/or progression rates during the follow-up period. This was presented in the ordered logit model as more than 6 and 4 times increase in the likelihood of recurrence and/or progression in patients who experience the expression of HER2 and c-KIT proteins respectively. This is consistent with the findings of many authors ${ }^{12,17,18}$ but different from what was reported by others. ${ }^{19,20}$ Notably, the expression of these proto-oncogenes is not consistent in reported studies of urothelial carcinoma. The technique of detecting these oncogenes may explain the heterogeneity of such results, where different studies used several different antibodies and varying non-comparable cytoplasmic and membrane staining patterns for IHC staining and its scoring. Also, a variety of methodological factors might influence IHC staining, including storage time, different primary antibodies, fixation method of paraffin-embedded tissues, different levels of positive and combining intensity and percentage scores. Furthermore, the immunostaining cutoff point was varied and arbitrarily selected among different studies. $^{21}$

Pooled data analysis exhibited a significant correlation between c-KIT expression and poor overall survival of patients with osteosarcoma and renal carcinoma, suggesting it to be an independent predictor of poor survival in these patients. ${ }^{22,23}$ However, these results should be interpreted cautiously, considering the limited studies included in this meta-analysis.

If both proteins were undetectable, the current study predicts a probability of experiencing no recurrence of $92 \%$, which gradually decreased to $24 \%$ when proteins were strongly expressed. However, the predicted probabilities of experiencing recurrence or having progression increase from $4 \%$ and $3 \%$ if no protein is observed to $19 \%$ and $55 \%$ when either protein is strongly expressed. $\mathrm{Li}$ et $\mathrm{al}^{24}$ detected the expression of HER2 protein in all evaluated cases of invasive micropapillary aggressive urothelial carcinoma, where more than $87 \%$ of cases had $\geq 2+$ protein expression, which was significantly higher than the $31 \%$ seen in conventional invasive cases, which 
A
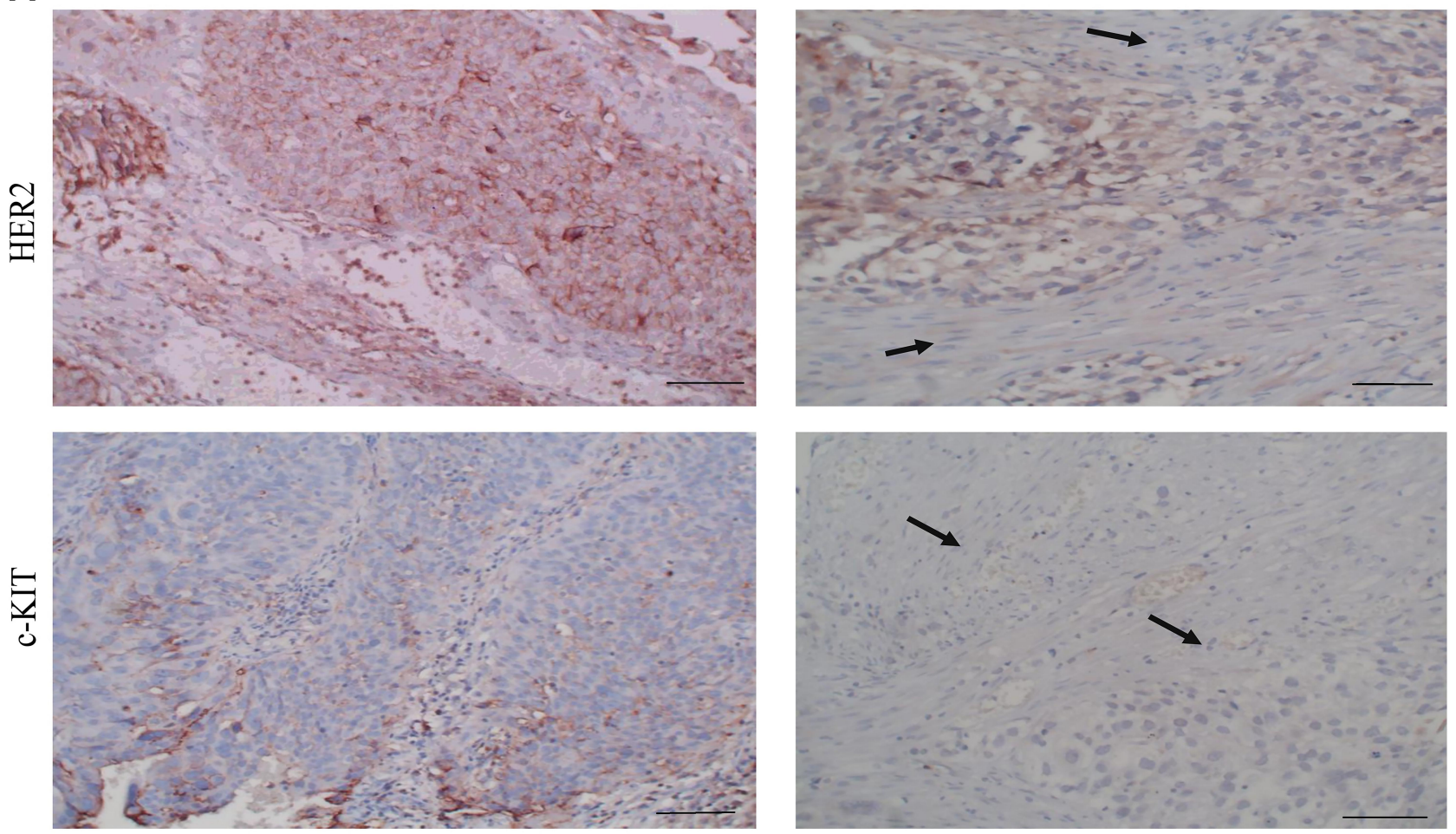

B
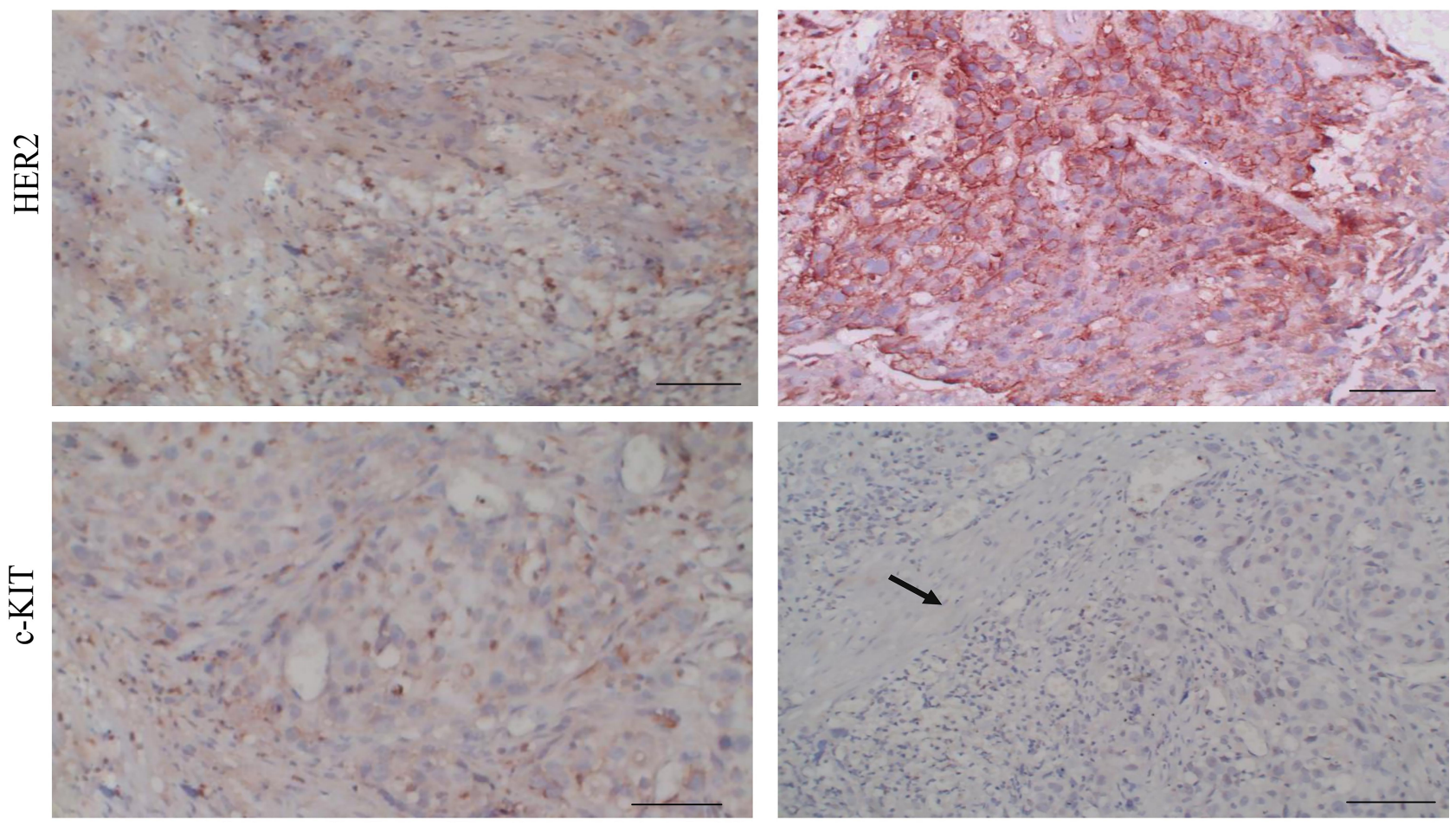

Figure I Expression of HER2 and c-KIT in progressive urothelial lesions. Representative immunohistochemical (IHC) expression for HER2 and c-KIT markers. The immunoreaction (brown) for HER2 and c-KIT was detected in the cytosol and cell membranes. (A) In low-grade NMIBC, tumor nests (black arrows) showed expression of HER2 as 2+, while that of c-KIT was weak and focal $(I+)(\mathrm{IHC}$ original magnification $\times 200$ ). In low-grade muscle-invasive BC, tumor nests (black arrows) are seen dissecting muscle bundles (black arrows). The expression of HER2 was reduced in comparison to NMIBC but detected in $50 \%$ of tumor cells and thus scored I+, while there was no expression for c-KIT. (IHC original magnification x200, scale bar $50 \mu \mathrm{m}$ ). NMIBC; non-muscle-invasive bladder carcinoma. (B) In high-grade NMIBC, tumor nests (black arrows) composed of malignant urothelial cells show weak and focal expression of both HER2 and c-KIT (I+) (IHC original magnification x200). In high-grade muscle-invasive BC, tumor nests are seen dissecting muscle bundles (black arrows). The expression of HER2 significantly increased in comparison to NMIBC (scored 2+), while there was no expression for c-KIT. (H\&E and IHC original magnification x200, scale bar $50 \mu \mathrm{m}$ ). Abbreviation: NMIBC, non-muscle-invasive bladder carcinoma. 
Table 2 Correlation Between Clinical and Pathological Features with Immunohistochemical Staining for HER2 and c-KIT Proteins

\begin{tabular}{|c|c|c|c|c|c|c|c|c|}
\hline \multicolumn{2}{|c|}{ Parameters } & \multirow{3}{*}{$\begin{array}{c}\begin{array}{c}\text { Total } \\
\mathrm{n}=100\end{array} \\
47\end{array}$} & \multicolumn{2}{|c|}{ HER2 } & \multirow{4}{*}{$\begin{array}{c}\boldsymbol{p} \text {-value } \\
0.09\end{array}$} & \multicolumn{2}{|c|}{ c-KIT } & \multirow{4}{*}{$\begin{array}{c}p \text {-value } \\
0.41\end{array}$} \\
\hline & & & \multirow{3}{*}{$\begin{array}{c}\begin{array}{c}\text { Positive } n=49 \\
\text { No (\%) }\end{array} \\
30(63.8) \\
19(35.8)\end{array}$} & \multirow{2}{*}{$\begin{array}{c}\text { Negative } \mathbf{n}=5 \text { I } \\
\text { No (\%) }\end{array}$} & & \multirow{2}{*}{$\begin{array}{c}\begin{array}{c}\text { Positive } n=38 \\
\text { No (\%) }\end{array} \\
20(42.6)\end{array}$} & \multirow{2}{*}{$\begin{array}{c}\begin{array}{c}\text { Negative } \mathbf{n}=\mathbf{6 2} \\
\text { No (\%) }\end{array} \\
27(57.4)\end{array}$} & \\
\hline Gender & Male & & & & & & & \\
\hline & Female & 53 & & $34(45.3)$ & & $18(34)$ & $35(66)$ & \\
\hline \multirow[t]{2}{*}{ Age/years } & $\leq 60$ & 69 & $4 \mathrm{I}(59.4)$ & $28(40.6)$ & \multirow[t]{2}{*}{$<0.001$} & $28(40.6)$ & $4 \mathrm{I}(59.4)$ & \multirow[t]{2}{*}{0.51} \\
\hline & $>60$ & 31 & $7(22.5)$ & $24(77.4)$ & & $10(32.3)$ & $21(67.7)$ & \\
\hline \multirow[t]{2}{*}{ Tumor size } & $\leq 3 \mathrm{~cm}$ & 54 & $20(37)$ & $34(63)$ & \multirow[t]{2}{*}{0.015} & $16(29.6)$ & $38(70.4)$ & \multirow[t]{2}{*}{0.07} \\
\hline & $>3 \mathrm{~cm}$ & 46 & $29(63)$ & $17(37)$ & & $22(47.8)$ & $24(52.2)$ & \\
\hline \multirow{2}{*}{$\begin{array}{l}\text { Tumor } \\
\text { number }\end{array}$} & Single & 84 & $38(45.2)$ & $46(54.8)$ & \multirow[t]{2}{*}{0.11} & $34(40.5)$ & $50(59.5)$ & \multirow[t]{2}{*}{0.28} \\
\hline & $\geq 2$ & 16 & II (68.8) & $5(3 \mid .2)$ & & $4(25)$ & $12(75)$ & \\
\hline \multirow[t]{2}{*}{$\mathrm{CIS}$} & Yes & 2 & $2(100)$ & $0(0)$ & \multirow[t]{2}{*}{1.00} & $2(100)$ & $0(0)$ & \multirow[t]{2}{*}{1.00} \\
\hline & NO & 0 & $0(0)$ & $0(0)$ & & $0(0)$ & $0(0)$ & \\
\hline \multirow{2}{*}{$\begin{array}{l}\text { Tumor } \\
\text { stage }\end{array}$} & $\mathrm{Ta}$ & 45 & $13(28.9)$ & 32 (7I.I) & \multirow[t]{2}{*}{$<0.001$} & $30(66.7)$ & $15(33.3)$ & \multirow[t]{2}{*}{$<0.001$} \\
\hline & TI & 55 & $40(72.7)$ & $15(27.3)$ & & $13(23.6)$ & $42(76.4)$ & \\
\hline \multirow{2}{*}{$\begin{array}{l}\text { Tumor } \\
\text { grade }\end{array}$} & Low & 53 & $21(39.6)$ & $32(60.4)$ & \multirow[t]{2}{*}{0.005} & $34(64.2)$ & $19(35.8)$ & \multirow[t]{2}{*}{$<0.001$} \\
\hline & High & 47 & $32(68.1)$ & 15 (31.9) & & $8(17)$ & $39(83)$ & \\
\hline
\end{tabular}

Table 3 Correlation Between HER2 Immunohistochemical Staining and Probabilities of Recurrence and Progression of the Primary Tumor

\begin{tabular}{|c|c|c|c|c|c|c|c|c|c|c|}
\hline \multirow[t]{2}{*}{ Outcome } & \multicolumn{3}{|c|}{ No Expression (0) } & \multicolumn{3}{|c|}{ Weakly Expressed (I+) } & \multicolumn{3}{|c|}{ Strongly Expressed (+2) } & \multirow[t]{2}{*}{ Total } \\
\hline & No & Coefficient & p-value & No & Coefficient & p-value & No & Coefficient & p-value & \\
\hline No recurrence & 38 & 0.85 & $<0.001$ & 11 & 0.83 & 0.001 & 3 & 0.15 & $<0.001$ & 52 \\
\hline Recurrence & 10 & 0.04 & 0.01 & 6 & 0.2 & 0.005 & 4 & 0.13 & $<0.001$ & 20 \\
\hline Progression & 14 & 0.01 & 0.02 & 3 & 0.14 & 0.002 & 11 & 0.74 & $<0.001$ & 28 \\
\hline Total & \multicolumn{3}{|c|}{62} & \multicolumn{3}{|c|}{20} & \multicolumn{3}{|c|}{18} & 100 \\
\hline
\end{tabular}

Table 4 Correlation Between c-KIT Immunohistochemical Staining and Probabilities of Recurrence and Progression of the Primary Tumor

\begin{tabular}{|c|c|c|c|c|c|c|c|c|c|c|}
\hline \multirow[t]{2}{*}{ Outcome } & \multicolumn{3}{|c|}{ No Expression (0) } & \multicolumn{3}{|c|}{ Weakly Expressed (I+) } & \multicolumn{3}{|c|}{ Strongly Expressed (+2) } & \multirow[t]{2}{*}{ Total } \\
\hline & No & Coefficient & p-value & No & Coefficient & p-value & No & Coefficient & p-value & \\
\hline No recurrence & 27 & 0.92 & $<0.001$ & 13 & 0.67 & 0.009 & 2 & 0.24 & $<0.001$ & 42 \\
\hline Recurrence & 12 & 0.04 & 0.05 & 7 & 0.16 & $<0.001$ & 5 & 0.19 & $<0.001$ & 24 \\
\hline Progression & 14 & 0.03 & 0.88 & 7 & 0.16 & 0.3 & 13 & 0.55 & $<0.001$ & 34 \\
\hline Total & \multicolumn{3}{|c|}{53} & \multicolumn{3}{|c|}{27} & \multicolumn{3}{|c|}{20} & 100 \\
\hline
\end{tabular}


Table 5 Multivariate Regression Analyses of Recurrence and Progression of the Primary Tumor and the Possible Risk Factors

\begin{tabular}{|l|l|l|}
\hline Recurrence/Progression & OR $(95 \%$ CI) & p-value \\
\hline Age of patients $>$ 60-year & I.0I $(0.84-1.04)$ & 0.589 \\
\hline Male gender & $1.45(0.92-1.63)$ & 0.067 \\
\hline Number of tumors $>2$ & $1.26(0.98-1.56)$ & 0.070 \\
\hline Tumor size $>3 \mathrm{~cm}$ & $6.60(4.8-7.2)$ & 0.004 \\
\hline HER2 expression & $6.25(3.4 I-8.13)$ & $<0.001$ \\
\hline c-KIT expression & $4.88(2.65-4.06)$ & $<0.001$ \\
\hline
\end{tabular}

is consistent with our results. Utilization of tissue sections rather than tissue microarray in the latter study, with its reduced potential sampling errors, may explain the overexpression of HER2 in all cases of urothelial carcinoma. Nevertheless, these results highlighted the significant correlation between HER2 overexpression and the worse prognosis of invasive urothelial carcinoma.

Of interest, our results show no score different expression patterns for HER2 and c-KIT at the time of recurrent lesions but in progression. Low-grade tumor cells show a decrease in the expression of both proteins with progression from lamina propria to muscle-invasive carcinoma. With high-grade urothelial lesions, however, there are different expression patterns of markers among tumor cells when progressed to muscle-invasive disease. In NMIBC, tumor cells showed weak and focal expression of HER2 when invades the lamina propria, while the reaction to c-KIT was very weak. With progression to muscle-invasive neoplasms, tumor cells maintain strong overexpression for HER2, but the expression to c-KIT becomes undetectable This would highlight the significant overexpression of the HER2 rather than c-KIT in progressive high-grade bladder cancer.

Similar to our results, Gandour et al previously confirmed that high-grade, muscle-invasive bladder cancer has a significant rate of $71 \%$ of HER 2 expression. ${ }^{25}$ On the other hand, Tsutsui et al found that loss of the c-KIT expression is associated with an advanced stage of breast cancer ${ }^{26}$ which is consistent with our finding in bladder cancer, in contrast to what has been observed by others. ${ }^{27}$ This may highlight the consistency of HER 2 expression in advanced high-grade bladder cancer, rather than the c-KIT which still controversial. The question now whether HER2-targeted therapies would be efficient for selected patients with high-grade NMIBC during adjuvant treatment after TURBT. This would be of utmost importance, especially with the current proven high prognostic sensitivity of the test in the current study. In addition, studies of HER2-targeting agents have not shown definitive clinical efficacy if used in unselected bladder cancer patients. $^{28}$

The multivariable logistic regression in a recent study demonstrated the epidermal growth factor cell overexpression to be a significant independent prognostic factor of disease recurrence and progression. ${ }^{29}$ These results could identify patients who may be unresponsive to adjuvant intravesical therapy after TURBT and may need early more aggressive management. Besides, overexpression of this protein on the NMIBC might represent an adverse prognostic marker of biologically aggressive disease, with an increased risk of tumor recurrence and progression. ${ }^{29,30}$ Similarly, it has been reported that high HER2 expression on tumor cells is considered an adverse prognostic factor of tumor recurrence and progression in NMIBC and thus these patients should be followed carefully. ${ }^{11}$

Unlike previous studies which have evaluated banked specimen for HER2 and c-KIT protein expression in bladder cancer, ${ }^{23-25}$ the current study focuses on prospectively managed patients in a standardized fashion. Up to our knowledge, this is the first study of its nature to evaluate and compare the resected primary bladder tumors with all the follow-up (at the time of recurrence and progression) TURBTs. Moreover, we showed that overexpression of HER2 rather than c-KIT proteins significantly correlated with progressive high-grade bladder cancer, and thus our results could identify patients who may be unresponsive to adjuvant intravesical therapy and may need early more aggressive management, with possible anti-HER2targeted therapies.

Despite its prospective nature, the current study is not without limitations. The studied patients' sample received BCG, which has a cytotoxic effect, and epirubicin, which inhibits the protein synthesis process, and thus the obtained results of the current study does not reflect the natural course of malignancy, but rather represents the findings with such treatment regimen. Selection bias may limit the interpretation of HER2 and c-KIT expression in bladder cancer. The IHC staining used to assess the expressions of these proto-oncogenes may influence the outcomes by affecting methodological factors, with consequent variability in the protein expression assessment, which would be considered another potential source of 

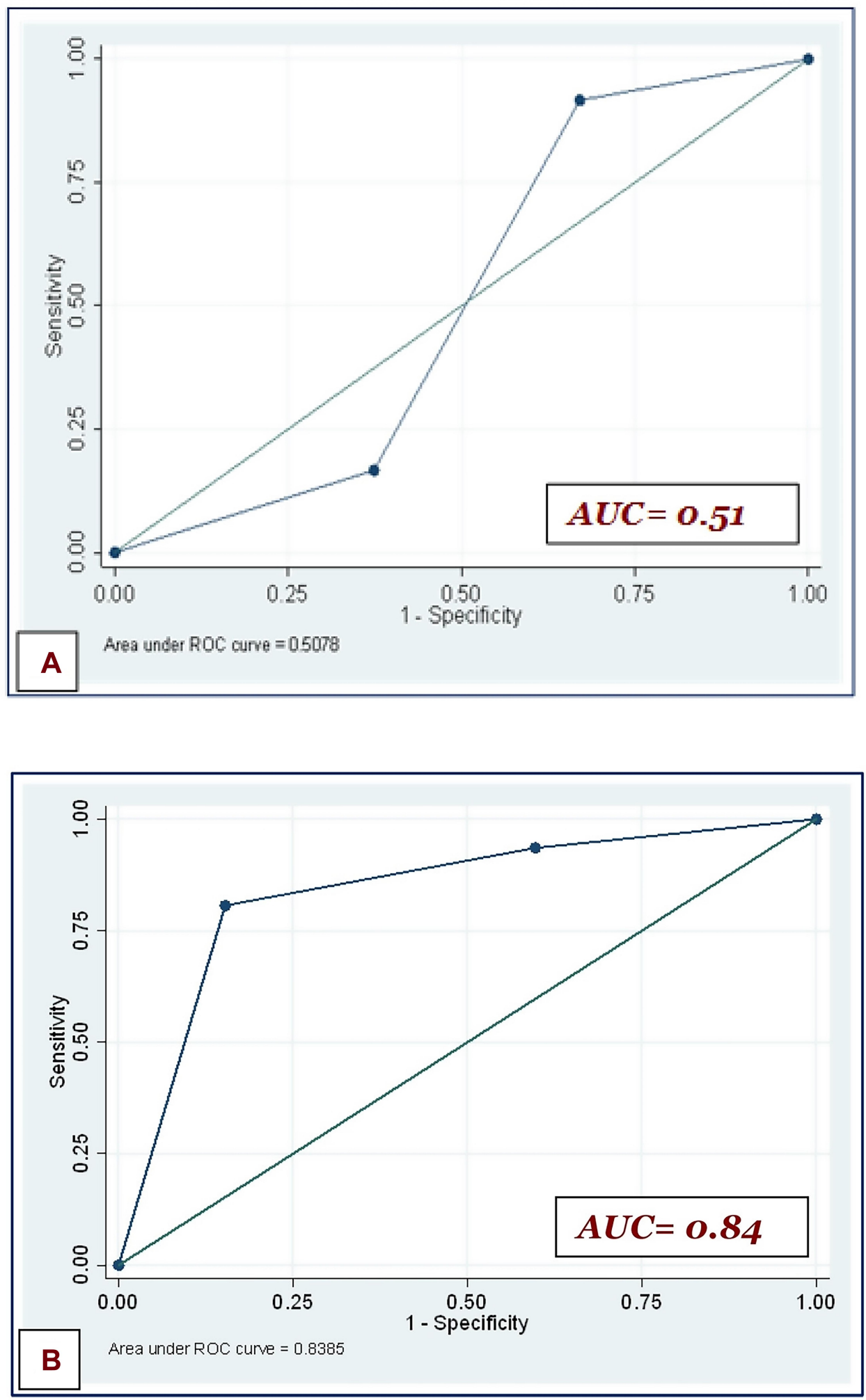

Figure 2 Receiver operating characteristic (ROC) curves for the impact of HER2 and c-KIT expression on recurrence (A) and progression (B).

bias. Furthermore, the impact of HER2 and c-KIT expression on the overall survival was not assessed in the current study, which may represent another source of controversy.

\section{Abbreviations}

AUC, area under the curve; BCG, Bacillus CalmetteGuérin; CIS, carcinoma in situ; HER2, human epidermal 
factor receptor 2; H\&E, hematoxylin and eosin; IHC, immunohistochemistry; NMIBC, non-muscle-invasive bladder cancer; MIBC, muscle-invasive bladder cancer; TURBT, transurethral resection of bladder tumor.

\section{Data Sharing Statement}

The datasets supporting the conclusions of this article are included within the article and its supplementary file.

\section{Ethics Approval and Consent to Participate}

The study was approved by the local institutional ethical committee faculty of medicine, Suez Canal university with IRB no (4169), and informed consent was obtained from all patients who participated in the study. All the procedures done were in accordance with the Declaration of Helsinki.

\section{Consent for Publication}

Written informed consent was obtained from the patients for publication of this study and any accompanying images. A copy of the written consent is available for review by the Editor-in-Chief of this journal.

\section{Acknowledgments}

The authors extend special thanks to M. Saad for his technical skills in preparing histopathological slides.

\section{Author Contributions}

All authors made a significant contribution to the work reported, whether that is in the conception, study design, execution, acquisition of data, analysis and interpretation, or in all these areas; took part in drafting, revising or critically reviewing the article; gave final approval of the version to be published; have agreed on the journal to which the article has been submitted; and agree to be accountable for all aspects of the work.

\section{Funding}

All clinicopathological studies in this study were funded by the authors.

\section{Disclosure}

None of the contributing authors have any conflict of interest, including specific financial interests or relationships and affiliations relevant to the subject matter or materials discussed in the manuscript.

\section{References}

1. Burger M, Catto JW, Dalbagni G, et al. Epidemiology and risk factors of urothelial bladder cancer. Eur Urol. 2013;63(2):234-241. doi:10. 1016/j.eururo.2012.07.033

2. Humphrey PA, Moch H, Cubilla AL, et al. The 2016 WHO classification of tumours of the urinary system and male genital organs-part B: prostate and bladder tumours. Eur Urol. 2016;70(1):106-119. doi:10.1016/j.eururo.2016.02.028

3. Chang SS, Cookson MS. Non-muscle-invasive bladder cancer: the role of radical cystectomy. Urology. 2005;66:917-922. doi:10.1016/j. urology.2005.05.003

4. Soloway MS, Sofer M, Vaidya A. Contemporary management of stage T1 transitional cell carcinoma of the bladder. J Urol. 2002; 167:1573-1583. doi:10.1016/S0022-5347(05)65157-9

5. Brausi M, Collette L, Kurth K, et al.; EORTC Genito-Urinary Tract Cancer Collaborative Group. Variability in the recurrence rate at first follow-up cystoscopy after TUR in stage Ta T1 transitional cell carcinoma of the bladder: a combined analysis of seven EORTC studies. Eur Urol. 2002;41(5):523-531. doi:10.1016/S0302-2838(02) 00068-4.

6. Ark JT, Keegan KA, Barocas DA, et al. Incidence and predictors of understanding in patients with clinical T1 urothelial carcinoma undergoing radical cystectomy. BJU Int. 2014;113(6):894-899. doi:10.11 11/bju. 12245

7. Babjuk M, Burger M, Compérat EM, et al. European association of urology guidelines on non-muscle-invasive bladder cancer (TaT1 and Carcinoma In Situ) - 2019 update. Eur Urol. 2019;76(5):639-657. doi:10.1016/j.eururo.2019.08.016

8. Fernandez-Gomez J, Madero R, Solsona E, et al. The EORTC tables overestimate the risk of recurrence and progression in patients with non-muscle-invasive bladder cancer treated with bacillus Calmette-Guerin: external validation of the EORTC risk tables. Eur Urol. 2011;60:423-430. doi:10.1016/j.eururo.2011.05.033

9. Yarden Y. Biology of HER2 and its importance in breast cancer. Oncology. 2001;61:1-13. doi:10.1159/000055396

10. Hussein S, Fathi A, Abouhashem NS, et al. SATB1 and Her2 as predictive molecular and immunohistochemical markers for urothelial cell carcinoma of the bladder. Cancer Biomarkers. 2020:1-11. doi: $10.3233 / \mathrm{cbm}-200072$.

11. Hansel DE, Swain E, Dreicer R, Tubbs RR. HER2 overexpression and amplification in urothelial carcinoma of the bladder are associated with MYC co-amplification in a subset of cases. Am J Clin Pathol. 2008;130:274-281. doi:10.1309/41VLTFX3YPP1HF6F

12. Bolenz C, Shariat SF, Karakiewicz PI, et al. Human epidermal growth factor receptor 2 expression status provides independent prognostic information in patients with urothelial carcinoma of the urinary bladder. BJU Int. 2010;106:1216-1222. doi:10.1111/j.1464410X.2009.09190.x

13. Bellmunt J, Werner L, Bamias A, et al. HER2 as a target in invasive urothelial carcinoma. Cancer Med. 2015;4:844-852. doi:10.1002/ cam 4.432

14. Divrik RT, Sahin AF, Yildirim U, Altok M, Zorlu F. Impact of routine second transurethral resection on the long-term outcome of patients with newly diagnosed pT1 urothelial carcinoma with respect to recurrence, progression rate, and disease-specific survival: a prospective randomised clinical trial. Eur Urol. 2010;58:185-190. doi:10.1016/j.eururo.2010.03.007

15. Eroglu A, Ekin RG, Koc G, Divrik RT. The prognostic value of routine second transurethral resection in patients with newly diagnosed stage pT1 non-muscle-invasive bladder cancer: results from randomized 10-year extension trial. Int J Clin Oncol. 2020; 25:698-704. doi:10.1007/s10147-019-01581-0

16. Zhau HE, Zhang X, von Eschenbach AC, et al. Amplification and expression of the c-erbB-2/neu proto-oncogene in human bladder cancer. Mol Carcinog. 1990;3:254-270. doi:10.1002/mc.2940030503 
17. Naruse K, Yamada Y, Nakamura K, et al. Potential of molecular targeted therapy of HER-2 and Cox-2 for invasive transitional cell carcinoma of the urinary bladder. Oncol Rep. 2010;23(6):1577-1583. doi:10.3892/or_00000798

18. Jimenez RE, Hussain M, Bianco FJ Jr, et al. Her-2/neu overexpression in muscle-invasive urothelial carcinoma of the bladder: prognostic significance and comparative analysis in primary and metastatic tumors. Clin Cancer Res. 2001;7(8):24 40-2447.

19. Jalali Nadoushan MR, Taheri T, Jouian N, Zaeri F. Overexpression of HER-2/neu oncogene and transitional cell carcinoma of bladder. Urol J. 2007;4(3):151-154.

20. Caner V, Turk NS, Duzcan F, et al. No strong association between HER-2/neu protein overexpression and gene amplification in high-grade invasive urothelial carcinomas. Pathol Oncol Res. 2008;14(3):261-266. doi:10.1007/s12253-008-9027-y

21. Simonetti S, Russo R, Ciancia G, Altieri V, De Rosa G, Insabato L. Role of polysomy 17 in transitional cell carcinoma of the bladder: immunohistochemical study of HER2/neu expression and fish analysis of c-erbB-2 gene and chromosome 17. Int J Surg Pathol. 2009;17 (3):198-205. doi:10.1177/1066896909333415

22. Terada T. Urinary bladder urothelial carcinoma with expression of KIT and PDGFRA and showing diverse differentiations into plasmacytoid, clear cell, acantholytic, nested, and spindle variants, and into adenocarcinoma, signet-ring cell carcinoma, small cell carcinoma, large cell carcinoma, and pleomorphic carcinoma. Int J Clin Exp Pathol. 2013;6(6):1150-1156.

23. Zhao F, Chen Y, Wu O. Prognostic value of C-KIT in cancer: a meta-analysis. Int J Clin Exp Pathol. 2014;7(3):1012-1021.
24. Li J, Jackson CL, Yang D, et al. Comparison of tyrosine kinase receptors HER2, EGFR, and VEGFR expression in micropapillary urothelial carcinoma with invasive urothelial carcinoma. Target Oncol. 2015;10(3):355-363. doi:10.1007/s11523-014-0341-x

25. Gandour-Edwards R, Lara PN Jr, Folkins AK, et al. Does HER2/neu expression provide prognostic information in patients with advanced urothelial carcinoma? Cancer. 2002;95(5):1009-1015. doi:10.1002/ cncr. 10808

26. Tsutsui S, Yasuda K, Suzuki K, et al. A loss of c-KIT expression is associated with an advanced stage and poor prognosis in breast cancer. Br J Cancer. 2006;94:1874-1878. doi:10.1038/sj.bjc.6603183

27. Charpin C, Giusiano S, Charfi S, et al. Quantitative immunohistochemical expression of c-KIT in breast carcinomas is predictive of patients' outcome. Br J Cancer. 2009;7:48-54. doi:10.1038/sj.bjc.6605113

28. Koshkin VS, O'Donnel P, Yu EY, Grivas P. Systematic review: targeting HER2 in bladder cancer. Bladder Cancer. 2019;5:1-12. doi:10.3233/BLC-180196

29. Di Maida F, Mari A, Scalici Gesolfo C, et al. Epidermal growth factor receptor (EGFR) cell expression during adjuvant treatment after transurethral resection for non-muscle-invasive bladder cancer: a new potential tool to identify patients at higher risk of disease progression. Clin Genitourin Cancer. 2019;17(4):e751-e758. doi:10.1016/j.clgc.2019.04.008

30. Abdelrahman AE, Rashed HE, Elkady E, Elsebai EA, El-Azony A, Matar I. Fatty acid synthase, Her2/neu, and E2F1 as prognostic markers of progression in non-muscle invasive bladder cancer. Ann Diagn Pathol. 2019;39:42-52. PMID: 30684846. doi:10.1016/j. anndiagpath.2019.01.002.
Research and Reports in Urology

\section{Publish your work in this journal}

Research and Reports in Urology is an international, peer-reviewed, open access journal publishing original research, reports, editorials, reviews and commentaries on all aspects of adult and pediatric urology in the clinic and laboratory including the following topics: Pathology, pathophysiology of urological disease; Investigation and

\section{Dovepress}

treatment of urological disease; Pharmacology of drugs used for the treatment of urological disease. The manuscript management system is completely online and includes a very quick and fair peer-review system, which is all easy to use. Visit http://www.dovepress.com/ testimonials.php to read real quotes from published authors. 